\title{
ALCOOLISMO FEMININO E GÊNERO: UMA ETNOGRAFIA EM UMA REUNIÃO FEMININA DE ALCOÓLICOS ANÔNIMOS
}

\author{
Edemilson Antunes de Campos $^{1}$,Andressa Gabrielle Teixeira do Valle ${ }^{1}$, Mariana Melo ${ }^{1}$ \\ e Marselle Ferreira Salles ${ }^{1}$ \\ 1Universidade de São Paulo, Brasil. edicampos@usp.br; andressa.teixeira512@gmail.com; mariana.ml@usp.br \\ marselle@usp.br
}

\begin{abstract}
Introdução: Nas últimas décadas, o alcoolismo feminino chama a atenção das autoridades médicas e sanitárias da sociedade brasileira. Nesse quadro, destaca-se a presença dos Alcoólicos Anônimos (A.A.), no interior do qual algumas mulheres encontram a possibilidade de tratamento do alcoolismo. Objetivo: Analisar o alcoolismo feminino de uma forma êmica, isto é, a partir dos significados do uso de álcool e do alcoolismo de mulheres que participam de uma reunião feminina de A.A. Métodos: Realizou-se uma pesquisa etnográfica, com observação participante, da reunião feminina de A.A. em um grupo de A.A., localizado na Zona Norte da Cidade de São Paulo, Brasil. Resultados: A análise dos dados revelou que os significados sobre o uso de álcool e o alcoolismo acionam um sistema de acusações, que envolve as relações de gênero próprias do universo sociocultural no qual as mulheres estão inseridas. Conclusão: $O$ alcoolismo feminino é uma "doença de gênero", ligada às relações assimétricas entre homens e mulheres em relação ao uso de bebidas alcoólatras em na sociedade brasileira, de modo que a reunião feminina de A.A. constitui uma "distinção positiva" para que as mulheres possam trocar suas experiências e, assim, realizar seu tratamento do alcoolismo.
\end{abstract}

Palavras-chave: Alcoolismo Feminino, Alcoólicos Anônimos; Etnografia; Gênero; Observação Participante

\section{FEMALE ALCOHOLISM AND GENDER: ETHNOGRAPHY IN A FEMALE MEETING OF ALCOHOLICS ANONYMOUS}

Introduction: In recent decades, female alcoholism has attracted the attention of medical and health authorities in Brazilian society. In this context, the presence of Alcoholics Anonymous (A.A.) stands out, within which some women find the possibility of treating alcoholism. Objective: To analyze female alcoholism in an emic way, that is, from the meanings of alcohol use and alcoholism of women who participate in a female AA meeting. Methods: An ethnographic research was carried out, with participant observation, of the meeting female $A A$ in a group of $A A$, located in the North Zone of the City of São Paulo, Brazil. Results: Data analysis revealed that the meanings about alcohol use and alcoholism trigger an accusation system, which involves gender relations typical of the socio-cultural universe in which women are inserted. Conclusion: Female alcoholism is a "gender disease", linked to asymmetrical relationships between men and women in relation to the use of alcoholic beverages in Brazilian society, so that the AA women's meeting constitutes a "positive distinction" for women can exchange their experiences and thus carry out their treatment of alcoholism.

Keywords: Female Alcoholism; Alcoholics Anonymous; Ethnography; Genre; Participant Observation

\section{INTRODUÇÃO}

Nas últimas décadas, o alcoolismo feminino chama a atenção das autoridades médicas e sanitárias na sociedade brasileira. Segundo as informações disponíveis no II Levantamento Nacional de Álcool e Drogas - LENAD -, realizado em 2012 pela Unidade de Álcool e Drogas da Universidade Federal de São Paulo - UNIAD/UNIFESP -, juntamente com o 
Instituto Nacional de Ciência e Tecnologia para Políticas Públicas do Álcool e Outras Drogas - INPAD -, envolvendo 163 municípios brasileiros apontam que 3,38\% das mulheres brasileiras são dependentes do álcool (Laranjeira, Madruga, Pinsky, Caetano, \& Mitsuhiro, 2014).

Nesse quadro, os Alcoólicos Anônimos (A.A.) surgem como uma forma de tratamento para as mulheres que se reconhecem como doentes do alcoolismo. O A.A. é, de acordo com sua literatura oficial, "uma irmandade de homens e mulheres que compartilham suas experiências, forças e esperanças, a fim de resolver seu problema comum e ajudar outros a se recuperarem do alcoolismo" (Alcoólicos Anônimos, 1996). Trata-se de um programa de recuperação, cujo objetivo é ajudar os alcoólicos a evitar o "primeiro gole" e, assim, manter a "sobriedade".

No Brasil, o primeiro grupo surgiu em 1947 e, atualmente, há cerca de 4700 grupos, que realizam cerca de 10900 reuniões de recuperação por semana1. No município de São Paulo há um total de 123 grupos de A.A., dos quais 32 estão na zona sul, 51 na zona leste, 15 na zona norte, 15 na zona oeste e 09 no grande centro, segundo dados do Escritório de Serviços Locais de Alcoólicos Anônimos do Estado de São Paulo - ESL22.

Em inventário realizado pela Junta de Serviços Gerais de A.A., no Brasil, apontou que 13\% de seus membros são mulheres e 87\%, são homens (Alcoólicos Anônimos, 2019). Assim, se é certa a prevalência do alcoolismo feminino nos dias atuais, ainda existe uma discrepância entre homens e mulheres quando se observa as possibilidades de tratamento. Essa discrepância é um indicador importante para o modo como o alcoolismo feminino envolve as relações de gênero na sociedade brasileira.

O conceito de gênero procura promover a distinção entre o dado e o construído, isto é, entre o natural e o sociocultural, destacando que a realidade é sempre uma realidade construída, particularmente aquela que diz respeito às relações entre o homem e a mulher (Heilborn, 2003). O conceito de gênero possui um valor heurístico, possibilitando compreender a construção das relações sociais entre homens e mulheres, marcadas pela hierarquia e pela desigualdade, vivenciadas em contextos sociais e culturais nos quais ambos estão inseridos. Ora, as relações de gênero, social e historicamente construidas, demarcam os

\footnotetext{
1'Disponível em: https://www.aa.org.br/sobre-o-a-a/o-grupo-de-a-a-localizacao/99-estrutura-de-a-a (Acesso em 27.02.2020).

Disponível em: http://www.alcoolicosanonimos.org.br/index.php/localizar-grupos/localizar-por-estado-cidade (Acesso em 27.02.2020)
} 
lugares sociais ocupados por homens e mulheres em relação ao uso de bebidas alcoólatras e ao alcoolismo em nossa sociedade.

Mas, tomar o gênero como categoria analítica pressupõe o caráter fundamentalmente relacional das construções de gênero. Assim, o alcoolismo das mulheres é marcado pelo estigma que envolve a transgressão do beber considerado compulsivo. Se para o homem o alcoolismo é reprovado, para as mulheres essa reprovação é amplificada devido às expectativas sobre o comportamento feminino, marcado pelas relações de gênero. Nessa linha, o estigma do alcoolismo feminino evidencia o conflito entre a transgressão e a apropriação de expectativas sociais de gênero, verificadas pelo não cumprimento de funções femininas socialmente valorizadas, como o cuidado aos filhos (Alzuguir, 2007). A pesquisa qualitativa em Ciências Sociais e Saúde tem se mostrado fundamental para o estudo do uso de álcool entre as mulheres, do alcoolismo feminino e suas formas de tratamento, com ênfase nas relações de gênero. Exemplo disso é a pesquisa que Garcia (2004) conduziu em grupos de A.A., localizados na cidade de Niterói, Estado do Rio de Janeiro, onde, para os membros do grupo, o ato de beber da mulher, em ambiente público, não importando a modalidade, constitui transgressão, reconhecida pela categorização mulheres que bebem.

Em seu estudo sobre alcoolismo, Cerclé (1998) aponta, por sua vez, que somente a partir dos anos 1950, o alcoolismo feminino passa a ser considerado um problema de saúde pública, particularmente com o status adquirido pelas mulheres (Cerclé, 1998, p. 60). Todavia, prevalece uma percepção diferente do alcoolismo feminino, em relação ao masculino, de modo que: "o alcoolismo feminino parece associado a uma maneira de ser global da mulher, enquanto que a imagem do "homem duplex" é uma característica do etilismo masculino" (Cerclé, 1998, p. 64).

O alcoolismo afeta a mulher em sua vida conjugal, no cuidado da casa e dos filhos, enquanto para o homem, o álcool não alteraria o suposto ethos masculino. Para o autor, a maior sensibilidade das mulheres ao estresse emocional e à ansiedade psicológica é um leitmotiv da literatura sobre o alcoolismo feminino (Cerclé, 1998, p. 67). Nessa linha, as representações do alcoolismo feminino encontram-se envolvidas pelas relações de gênero, de maneira a afetar a identidade social da mulher alcoólatra.

Fainzang (2007) também ressalta em seu estudo a importância das relações de gênero na explicação das causas do alcoolismo. Para a autora: "os discursos da causalidade são fruto 
de uma elaboração cultural, no sentido em que o laço estabelecido entre uma dada causa e o alcoolismo responde a uma necessidade social, a de se conformar à imagem resultante da construção social das categorias de sexo." (Fainzang, 2007, p. 43). Nessa linha, há uma tendência a priorizar as "causas psicológicas ou orgânicas" do alcoolismo feminino, tais como: "depressão", "fragilidade", "nervos", "metabolismo", ao passo que para o alcoolismo masculino são evocadas "causas sociológicas": pressão social, desemprego, más condições de trabalho (Fainzang, 2007).

As mulheres são apresentadas, assim, como necessariamente vulneráveis. Logo, elas seriam alcoólatras porque seriam vulneráveis. Para os homens, as "causas" do alcoolismo seriam exógenas, enquanto para as mulheres, as causas seriam endógenas, pois, elas seriam consideradas, intrinsecamente, frágeis e vulneráveis (Fainzang, 2007). Em suma, a noção de causalidade do alcoolismo deve levar em conta o fato de que a "interpretação causal é o resultado de uma construção coletiva sujeita àquela das categorias de sexo" (Fainzang, 2007, p. 43).

Em estudo anterior (Campos e Reis, 2010) feito com mulheres em tratamento em um centro de referência para o tratamento do alcoolismo na cidade de São Paulo, encontramos que as representações sobre o uso do álcool estão ligadas às relações familiares, profissionais e de gênero, identificando-as como "mulheres que abusam do álcool", isto é, mulheres que não cumprem suas obrigações sociais nas esferas da família e do trabalho.

Alzuguir (2014) também analisa o modo como as relações de gênero incidem sobre o tratamento do alcoolismo feminino, de maneira que as mulheres evidenciam as tensões entre o uso do álcool, as obrigações no trabalho e as expectativas sociais femininas. Com efeito, o tratamento do alcoolismo é envolvido pelas moralidades próprias às relações de gênero nas quais mulheres estão inseridas. Nessa linha, o objetivo deste artigo é o de compreender os significados do uso do álcool e do alcoolismo, ligados às relações de gênero, para as mulheres em tratamento em A.A, a partir de uma etnografia em uma Reunião Feminina em um grupo de A.A.

\section{MÉTODO}

Foi realizada uma pesquisa qualitativa, com abordagem etnográfica, entre agosto e dezembro de 2019, em uma Reunião Feminina de A.A., em um grupo de A.A., localizado na Zona Norte da Cidade de São Paulo, Brasil. O projeto de pesquisa foi aprovado pelo Comitê de Ética em Pesquisa da Escola de Artes, Ciências e Humanidades, da Universidade de 
São Paulo (CEP-EACH/USP). As mulheres serão tratadas, aqui, por nomes fictícios, como forma de garantir o anonimato e o sigilo de suas informações.

A metodologia escolhida para realização desta pesquisa foi a etnografia, valendo-se da observação participante, que tem como objetivo compreender cientificamente dada realidade sociocultural, a partir do ponto de vista "nativo" (Nakamura, 2009 e Victora, Knauth e Hansen, 2000). Trata-se de um método utilizado, tradicionalmente, pela Antropologia, com o objetivo de compreender o ponto de vista dos sujeitos da pesquisa, a partir dos significados que determinadas práticas sociais têm para aqueles que as vivenciam.

A observação participante prioriza o contato faca-a-face do pesquisador com o grupo estudado, participando de todas as atividades, observando o que os membros do grupo fazem no seu interior (WHO, 1994), o que permitiu compreender o tratamento do alcoolismo feminino dentro da reunião feminina de A.A.

A etnografia se mostra fundamental para o estudo do alcoolismo feminino por dois motivos: em primeiro lugar, por se tratar de um tema envolvido pelo estigma e o preconceito em relação às mulheres alcoólatras, a observação participante em um grupo de A.A., permite que as mulheres que se reconhecem doentes, possam falar de si mesmas sem a pressão moral da culpa e da vergonha, uma vez que o grupo de A.A. proporciona aos seus membros a construção do doente alcoólico como identidade redentora (Neves, 2004), por meio de uma linguagem da doença, a partir da qual elas reorganizam suas vidas e ressignificam suas experiências (Campos, 2010). Em segundo lugar, o método da etnografia permite a compreensão das relações entre o que as pessoas dizem e o que elas fazem, pois, as ações nem sempre correspondem às racionalizações (Fainzang, 2007 e Victora, Kanauth e Hassen, 2000). Nesse sentido, a observação participante na reunião feminina de A.A., permite compreender o alcoolismo feminino de maneira êmica, isto é, tal como ele é concebido e gerido pelas mulheres alcoólatras em recuperação. Com isso, pode-se observar as práticas das mulheres no momento em que estão em tratamento, compartilhando suas experiências dos tempos do alcoolismo ativo.

Minha participação nas reuniões foi decidida pela chamada "consciência coletiva" do grupo, após eu entrar em contato com o Escritório de Serviços Locais de A.A. e explicar o tema de minha pesquisa. Assim, uma companheira, responsável pela coordenação das reuniões femininas, entrou em contato comigo e consultou as demais mulheres de A.A. Dessa maneira, o grupo decidiu que eu poderia realizar a observação participante nas reuniões femininas. 
Com isso, realizou-se um itinerário etnográfico no sentido estabelecido por Geertz (1989), a saber, uma "descrição densa", na qual se busca compreender os significados que dão sentido aos atos cotidianos, tornando-os inteligíveis para aqueles que os praticam. Assim, procurou-se compreender os significados do uso do álcool e do alcoolismo para as mulheres alcoólatras, que participam da Reunião Feminina de A.A.

A escolha desse grupo para a realização da pesquisa deveu-se, em primeiro lugar, por um ser um grupo de A.A., consolidado com 38 anos de existência, realizando as chamadas reuniões de recuperação, nas quais os membros de A.A., compartilham suas experiências, ajudando-se mutuamente para superar a doença do alcoolismo. Em segundo lugar, por ser um grupo em que há 31 anos são realizadas as reuniões femininas de A.A. A reunião feminina é uma reunião de recuperação em que só participam mulheres que se reconhecem como portadoras do alcoolismo. Essas reuniões ocorrem aos sábados das 14h00 às 16h00 e tem em média a presença de 15 mulheres, com idade entre 30 e 45 anos. A maioria das mulheres é casada, sendo algumas delas com membros do grupo de A.A.

Na Cidade de São Paulo, apenas, 09 grupos de A.A., realizam as reuniões femininas, de modo que algumas mulheres que participam da reunião, no grupo estudado, vêm de outras regiões distantes ou mesmo de cidades vizinhas à São Paulo. A maioria vem ao grupo de transporte público, tanto o ônibus como o metrô.

O grupo fica localizado em bairro de classe média baixa de São Paulo, próximo a lojas, bares e padaria.

Devido à proximidade da estação do metrô e terminal de ônibus, as ruas próximas ao grupo têm um fluxo grande de pessoas, muitas aproveitando o sábado para fazerem compras ou mesmo passear. Assim, é comum algumas "companheiras", como são chamadas as mulheres de A.A., chegarem à reunião com sacolas e pacotes de presentes.

A sala em que ocorrem as reuniões é alugada, o que mostra a autonomia financeira do grupo, e paga com recursos arrecadados durante as reuniões. O acesso à sala de reuniões se dá por meio de uma escada, que acessa uma pequena copa, com uma pia, com uma cafeteira e água. O café é preparado pela companheira responsável por abrir a sala, que também secretaria as reuniões. Tudo é custeado com recursos do grupo, mas é comum alguma companheira levar um bolo e bolachas que são degustados no intervalo das reuniões. 
Ao passarmos pela copa, adentramos a sala de reuniões, que é toda pintada em azul e branco, as cores características de A.A. A sala dispõe de uma mesa na entrada, em que encontramos o livro de presença e um saco com fichas numeradas, que cada companheira que desejar deve pegar e que serão sorteadas para definir a ordem das "partilhas" durante a reunião. A sala dispõe de cadeiras enfileiradas e à frente uma mesa, que será usada pelo coordenador da reunião, com alguns livros da literatura do grupo e, ao lado, uma cadeira que usada pela mulher sorteada para fazer a partilha. As paredes da sala são decoradas com três quadros grandes, em que encontramos os Doze Passos, as Dozes Tradições e os Doze Conceitos de A.A. Além disso, temos diversos painéis menores, com os seguintes dizeres: "Vá com calma", "Só por hoje", "Evite o primeiro gole", "Você é a pessoa mais importante dessa reunião". Também encontramos um quadro negro, no qual é descrita a agenda de atividades mensal do grupo, bem como o nome dos coordenadores das reuniões do mês corrente.

A reunião se inicia, pontualmente, as $14 \mathrm{~h} 00$, com a leitura de um preâmbulo pela coordenadora e, em seguida, é feita a Oração da Serenidade. Após a leitura da Reflexão Diária (Alcoólicos Anônimos, 2000), o coordenador sorteia a primeira ficha, cuja companheira terá 10 minutos para fazer sua partilha, que todas ouvem em silêncio. Ao término da partilha, as companheiras agradecem. Antes do intervalo, o coordenador evoca a Sétima Tradição e é passado um saco para recolher as doações, que cada companheira é livre para contribuir com o que puder. Às $15 \mathrm{~h} 00$, é realizado um intervalo para o café, que tem duração de 15 minutos. Esse momento é importante, pois, as companheiras conversam entre si sobre assuntos diversos, o que diferencia da seriedade do momento das partilhas. Ao término da reunião, todas as companheiras fazem a Oração da Serenidade e se despendem com abraços e sorrisos. Assim elas partem para seus afazeres do final de semana, após mais uma reunião feminina de A.A.

\section{RESULTADOS}

Esta pesquisa foi conduzida em uma perspectiva teórico-metodológica interpretativa e compreensiva, na qual se buscou compreender os significados que envolve um determinado fenômeno social, qual seja, a maneira como as mulheres explicam e concebem o uso do álcool e o alcoolismo dentro do modelo terapêutico de A.A.

A partir da observação participante nas reuniões femininas A.A., foi possível identificar as seguintes categorias de análise: "Uso de álcool e gênero", "Alcoolismo feminino e gênero" e 
"Mulher em tratamento em Alcoólicos Anônimos e gênero", que serão apresentadas a seguir.

\subsection{Uso de álcool e gênero}

Esta categoria refere-se aos significados que as mulheres atribuem ao uso que faziam do álcool, relacionados às relações de gênero em que estavam inseridas. Com efeito, o uso do álcool feito, em geral, sozinhas em casa: "Quando eu bebia, eu escondia as garrafas em casa. Eu não bebia na rua" (Paula, reunião feminina de A.A., 31/08/19).

Beber em público, em um bar, é considerado um ato tipicamente masculino, o que reforça a imagem da mulher cujo lugar por excelência é a casa, zelando pela ordem do lar e cuidando dos filhos (Garcia, 2004).

Os significados do uso do álcool para as mulheres desse estudo estão envolvidos pelas relações de gênero, que estabelecem uma assimetria entre homens e mulheres em relação ao consumo de bebidas alcoólicas: "O homem quando bebe, é social; quando a mulher bebe, ela é sem vergonha" (lara, reunião feminina, 14/09/19).

Além de revelar a força do estigma associado à "mulher que bebe", lara deixa entrever uma representação da mulher que faz um uso de álcool como uma mulher "sem vergonha". Ou seja, a mulher que bebe comporta-se de maneira oposta à mulher considerada "honesta", isto é, aquela que cumpre seu papel social de "esposa" e "mãe", zelando pela ordem da casa.

Um sentimento de vergonha em relação ao uso de álcool também é comumente expresso pelas mulheres, durante a reunião feminina: "Eu ia na padaria e comprava muitas coisas e uma garrafa de vodka. Eu mudava o lugar das compras, para despistar. Até que eu dia, a dona da padaria me disse que eu não precisava comprar todas aquelas coisas, porque era só a vodka que eu queria. Isso me deu uma vergonha muito grande" (Joana, reunião feminina, 14/09/19).

Esse sentimento de vergonha aponta para as moralidades em envolvem as relações de gênero na sociedade brasileira, definindo os significados sobre o uso de álcool pelas mulheres em tratamento em A.A.. Esses achados corroboram com os de Alzuguir (2007) em seu estudo com mulheres em tratamento para o alcoolismo em um serviço público de saúde na Cidade do Rio de Janeiro, no qual o sentimento de vergonha é refletido na estratégia de beber mais intensamente fora do olhar público, no âmbito privado, de sua residência. 
A vergonha de beber em público se acentua no momento da perda de controle sobre álcool, o momento em que se rompe com as regras morais que regulam o beber feminino e denota a manifestação do alcoolismo: "Eu cheguei a morar na rua. Eu dormia junto com a garrafa. Quando eu acordava, a primeira coisa que eu fazia era beber" (Marli, reunião feminina, 28/09/19).

\subsection{Alcoolismo feminino e gênero}

Essa categoria de análise informa sobre o modo como os significados do alcoolismo feminino estão diretamente relacionados à lógica de gênero que rege as narrativas das mulheres que participam da reunião feminina de A.A: "Se o alcoolismo do homem é ruim, o da mulher é muito pior" (Mara, reunião feminina, 28/09/2019). Se a vergonha está associada ao ato de beber feminino, o alcoolismo feminino está relacionado à degradação moral da mulher, o que faz com que ele seja considerado "pior" do que o masculino.

Nas partilhas feitas durante a reunião feminina, o alcoolismo feminino assume os contornos de uma "doença físico-moral" , que afeta tanto o âmbito físico/orgânico como o âmbito moral da vida da mulher alcoólatra. $O$ alcoolismo feminino é traduzido tanto a partir de seus efeitos sobre o organismo, atingindo o âmbito físico e mental do doente, como a partir de seus efeitos sobre o plano moral, afetando, sobretudo, o âmbito relacional da família. É isso que observamos na partilha de Helena: "Minha vida começou pelo meio e não pelo começo. Aos 14 e 15 anos, aí comecei a beber de verdade e eu matava aula pra beber. Eu sentia que dentro de mim era diferente; eu me sentia diferente. Eu achava que podia fazer muita coisa, tinha a cabeça voltada para o álcool. Eu não era uma pessoa que programava as coisas. Eu não queria parar de beber, eu gostava dos efeitos do álcool. Eu comecei a beber para fazer coisas diferentes, eu não sabia que existia a doença do alcoolismo. Tive filhos muito cedo. Não me casei. Eu sempre prometia que eu ia mudar; que eu ia ter uma vida normal. Mas, só queria beber, eu não queria saber de cuidar de meus filhos. Minha mãe me falava: "Você só pensa em beber". Uma bêbada como eu não tinha responsabilidade com vida, com os meus filhos. Muitas vezes, eu acordava de madrugada e ia sair para beber. Eu gostava de viver a noite. Chegou uma hora, eu não sabia que tinha a doença do alcoolismo. Que através dessa doença, minha vida foi só trauma, só derrota. Eu tive apagamentos, eu não me lembrava do que eu fazia. Minha irmã, que a mesma idade que eu; ela morreu e eu não

\footnotetext{
${ }^{3}$ A "doença físico-moral" é entendida, aqui, no sentido proposto por Duarte (2003, p. 177) e dizem respeito "às condições, situações ou eventos de vida considerados irregulares ou anormais pelos sujeitos sociais e que envolvam ou afetem não apenas sua mais imediata corporalidade, mas também sua vida moral, seus sentimentos e sua auto-representação".
} 
consegui ir ao enterro dela; eu bebi tanto, que eu não fui. Como explicar isso para minha família? Como eles vão entender? A doença leva à loucura" (Helena, reunião feminina, 17/12/19).

Uma análise compreensiva dessa narrativa aponta para os significados do alcoolismo que deslizam entre o plano físico - apagamento, loucura - e o plano moral - nãoresponsabilidade no cuidado com os filhos e com a família - da pessoa. Helena externa o sentimento de culpa e a vergonha por ter correspondido ao que se espera de uma mulhermãe, ou seja, uma mulher que é responsável pelo cuidado dos filhos.

A responsabilidade não é uma categoria ético-abstrata, mas é a responsabilidade-obrigação em relação à sua família e aos seus filhos. Como lembra Sarti (2005), a mulher desempenha na família um papel diferencial e complementar em relação ao homem, de maneira que é justamente de sua condição de "dona de casa" que se irradia as marcas fundamentais de sua autoridade no espaço da casa.

A análise dos dados revela que o alcoolismo feminino pode ser considerado como uma "doença de gênero", cujos significados acionam um sistema de acusações, que envolve as relações de gênero próprias do universo sociocultural no qual as mulheres estão inseridas.

\subsection{Mulher em tratamento em A.A. e gênero.}

Essa categoria de análise sintetiza a aceitação por parte das mulheres de que têm a doença do alcoolismo: "Quando eu cheguei nessa sala, me disseram que eu tinha uma doença que não tem cura.

Eu não me considerava alcoólatra, eu não bebia na rua" (Jussara, reunião feminina, 19/10/19). A entrada em A.A., marca o início do tratamento do alcoolismo e o reconhecimento de que são doentes.

O modelo terapêutico de A.A., opera como um sistema, que permite a ressignificação da experiência vivida pelas mulheres. Na fala de Jussara vê-se claramente que para ela o alcoolismo se relacionava com um modo considerado desregrado de beber "na rua", o que

\footnotetext{
A noção de "doença de gênero" é usada por Löwy (2013) em sua análise sobre o câncer cervical e as relações de gênero definidas historicamente. Para a autora, a visibilidade do câncer do colo do útero, ao longo da história, está diretamente ligada às questões de gênero, isto é, aos modos como a relação diferencial entre homens e mulheres é construída social e historicamente. Com efeito, apesar da grande magnitude do câncer de próstata entre os homens, o câncer cervical tem uma maior visibilidade, fazendo parte de campanhas públicas para a promoção da saúde da mulher. Isso faz, segundo Löwy (2013, p. 80), do câncer do colo do útero uma "doença de gênero".
} 
contraria a imagem da mulher honesta, que só bebia em casa. Ao chegar à sala de A.A., ela passa a incorporar o significado do alcoolismo concebido como uma doença incurável.

A chegada à sala de A.A., é marcada pela ruptura com as regras morais, que definem o papel da mulher, como mãe responsável pelo cuidado dos filhos: "Eu entrei A.A., porque meu marido ameaçou a tirar meu filho de mim. Aí, eu percebi que estava no fundo do poço" (Silvia, reunião feminina, 07/09/19). A imagem do fundo-do-poço é usada pelos membros de AA para significar a situação-limite, derradeira, que é vivida sob a forma de múltiplas perdas envolvendo, notadamente, o plano moral da família. Para Silvia, o fundo-do-poço relacionase com a possibilidade da perda da guarda do filho, isto é, com a perda do papel de mãe responsável pelo cuidado do filho.

A entrada em A.A. significa a recuperação da responsabilidade: "Hoje, eu posso escolher não beber. Antes de entrar em A.A., eu não podia escolher. O A.A. devolveu minha responsabilidade" (Paula, reunião feminina, 31/08/19).

Mas, se a entrada em A.A., significa, para a mulher, a condição para a recuperação de sua responsabilidade, como compreender o papel da reunião feminina de A.A.? Por que as mulheres necessitam de uma reunião na qual somente elas fazem parte? Como o modelo terapêutico de A.A. lida com o alcoolismo feminino? Como as relações de gênero presentes em nossa sociedade incidem sobre o modelo terapêutico de A.A., no tratamento do alcoolismo?

Essas questões são importantes se considerarmos que o A.A. é um modelo terapêutico voltado, fundamentalmente, à recuperação individual de seus membros, que se tornaram dependentes do álcool (Alcoólicos Anônimos, 2002). Para Mäkelä (1991, p. 1406), o A.A., é "uma forma altamente individualizada de atribuir sentido ao mundo". Com efeito, a fim de que a recuperação tenha início, o indivíduo precisa reconhecer pessoalmente seu próprio alcoolismo, de maneira que a condição de ser alcoólico é tão fundamental que superaria quaisquer outras diferenças individuais e sociais.

O modelo terapêutico de A.A., não discrimina ninguém que queira parar de beber. Ao definir o alcoolismo como uma doença, o modelo de A.A., confere uma "distinção positiva", uma dignidade e seriedade ao doente alcoólico (Soares, 1999). Alcoólicos Anônimos representam uma mudança de paradigma na compreensão do alcoolismo, ao concebê-lo como uma doença incurável. 
As mulheres reconhecem a importância da reunião feminina de A.A.: "Eu gosto de participar das reuniões femininas. Nessa reunião, eu vejo que as companheiras falam de mim. As companheiras falam da dor da alma. Isso me toca" (Paula, reunião feminina, 31/08/19).

A reunião feminina é o reconhecimento de que as relações de gênero, que envolvem o alcoolismo feminino, perpassam também o tratamento do alcoolismo no interior de A.A. As relações de gênero definem o processo de adesão das mulheres ao modelo terapêutico de A.A., e a busca de tratamento em A.A. A reunião feminina, composta apenas por mulheres, aponta para o modo como as relações de gênero, presentes em nossa sociedade, incidem diretamente sobre o modo como as mulheres vivenciam a experiência do alcoolismo dentro do A.A.

Para Paula, vivenciar o alcoolismo no interior de A.A., significa compartilhar com as companheiras a "dor da alma". Essa definição do alcoolismo feminino possui um valor heurístico uma vez que permite entrever tanto os sentidos do adoecer e do sofrimento, fundados nas relações de gênero presentes no contexto sociocultural no qual as mulheres estão inseridas e que definem de forma assimétrica o uso de alcool e o alcoolismo de homens e mulheres, como a importância da reunião feminina de A.A., para o tratamento das mulheres alcoólatras.

A "dor da alma" significa uma dor interna, profunda, um sofrimento vivido muitas vezes na solidão da casa e que só na reunião feminina encontra possibilidade de vir à tona. Em conversa com Helena, ela me disse que a reunião feminina é importante, porque permite que as mulheres compartilhem experiências que não compartilhariam em uma reunião que houvesse a presença de homens. A "dor da alma" evidencia o isolamento vivido pelas mulheres alcoólatras e as dificuldades que elas enfrentam para expor seu alcoolismo, uma vez que, enquanto o alcoolismo masculino é reconhecido, o feminino é condenado duplamente, por ser algo que macula a representação da mulher honesta, que não deveria fazer um uso de álcool e cuidar da casa e dos filhos.

O alcoolismo feminino é uma "doença de gênero", cercado pelo estigma que ainda vê a mulher alcoólatra como "degenerada", de maneira que a reunião feminina é uma espécie de "distinção positiva", que confere uma dignidade e seriedade à mulher alcoólatra e lhe assegura um espaço próprio, um lugar moralmente privilegiado, que opera como um antídoto ao preconceito e ao estigma que envolve o alcoolismo feminino, permitindo às mulheres alcoólatras compartilhar a "dor da alma". 


\section{CONSIDERAÇÕES FINAIS}

A etnografia realizada em uma reunião feminina de A.A., mostra como as mulheres alcoólatras significam o uso de álcool e o alcoolismo a partir das relações de gênero presentes na sociedade brasileira, que definem de forma assimétrica o uso de álcool entre homens e mulheres.

A análise dos dados revelou que os significados sobre o uso de álcool e o alcoolismo, a partir de três categorias de análise: "uso do álcool e gênero", "alcoolismo feminino e gênero" e "Mulher em tratamento em A.A. e gênero". Essas categorias evidenciam que o uso de álcool e o alcoolismo feminino acionam um sistema de acusações, que envolve as relações de gênero próprias do universo sociocultural no qual as mulheres estão inseridas. Com efeito, o alcoolismo feminino pode ser considerado uma "doença de gênero", que afeta o plano físico e moral da mulher alcoólatra, comprometendo sua responsabilidade nos afazeres domésticos e no cuidado com os filhos.

Por meio da observação participante foi possível vivenciar junto com as mulheres alcoólatras seu tratamento do alcoolismo e, por essa via, compreender os significados do uso do álcool e do alcoolismo construídos no interior de uma reunião feminina de A.A. A etnografia mostra-se, assim, um método fundamental para a pesquisa sobre o alcoolismo feminino e sua forma de tratamento na medida em que permite a compreensão êmica do alcoolismo feminino, isto é, a partir da observação da maneira como as mulheres concebem e vivenciam o tratamento do alcoolismo sem as pressões da culpa e do preconceito. A etnografia evidencia a relação entre o fazer e o dizer, permitindo compreender os significados do alcoolismo feminino e de seu tratamento por meio da observação do que as mulheres dizem e fazem durante a reunião feminina de A.A.

Nas reuniões femininas, o alcoolismo é significado como a "dor da alma"; um sofrimento profundo que as mulheres vivenciam muitas vezes na solidão de suas casas. A reunião feminina é o reconhecimento, por parte de A.A., de que o alcoolismo feminino é uma "doença de gênero" e que as mulheres necessitam de uma "distinção positiva", isto é, um espaço seguro, onde possam compartilhar suas experiências e encontrar o apoio mútuo necessário para aliviar a "dor da alma".

Agradecimentos: Esse artigo é derivado de Auxílio à Pesquisa, processo número: 2017/18535-9, Fundação de Amparo à Pesquisa do Estado de São Paulo (FAPESP), a quem agradecemos o apoio. 


\section{REFERÊNCIAS}

Alcoólicos Anônimos (1996). O Grupo de AA: onde tudo começa. São Paulo: JUNAAB - Junta de Serviços Gerais de Alcoólicos Anônimos.

Alcoólicos Anônimos (2000). Reflexões Diárias. São Paulo: JUNAAB - Junta de Serviços Gerais de Alcoólicos Anônimos.

Alcoólicos Anônimos (2002). Alcoólicos Anônimos em sua comunidade, São Paulo: JUNAAB - Junta de Serviços Gerais de Alcoólicos Anônimos.

Alcoólicos Anônimos (2019). Quem somos nós? Inventário de A.A. no Brasil. In. Vivência - Revista Brasileira de Alcoólicos Anônimos, São Paulo: JUNAAB - Junta de Serviços Gerais de Alcoólicos Anônimos.

Alzuguir, F. V. (2007). Tapando o Sol com a peneira: bebida e relações de gênero na trajetória de mulheres alcoólatras. Saúde em Debate. Rio de Janeiro, 31(75), 124-134.

Alzuguir, F. V. (2014). A carreira moral da vergonha na visão de homens e mulheres alcoólatras. Physis Revista de Saúde Coletiva, Rio de Janeiro, 24(1),11-29.

Campos, E. A. (2010). "Nosso remédio é a palavra": uma etnografia sobre modelo terapêutico de Alcoólicos Anônimos. Rio de Janeiro: Ed. Fiocruz.

Campos. E.A., \& Reis, J.G. (2010). Representações sobre o uso de álcool por mulheres em tratamento em um centro de referência da cidade de São Paulo - Brasil. Interface, Botucatu , 14(34), 539-550.

Cerclé, A. (1998). L’alcoolisme. Paris: Flamarion.

Duarte, L. F. D. (2003). Indivíduo e pessoa na experiência da doença. Ciência e Saúde Coletiva. 8(1), 173-183.

Fainzang, S. (2007). Curar-se do álcool: antropologia de uma luta contra o alcoolismo. Niterói : Intertexto.

Garcia, A. M. (2004). E o verbo (re) fez o homem: estudo do processo de conversão do alcoólico ativo em alcoólico passivo. Niterói: Intertexto.

Geertz, C. (1989). A interpretação das culturas. Rio de Janeiro: LTC.

Heilborn, M. L. (2003). Articulando gênero, sexo e sexualidade: diferença na saúde. In. Goldenberg, P., Marsiglia, R. M. G., \& Gomes, M. H. A. (coord.) O clássico e o novo: tendências, objetos e abordagens em ciências sociais e saúde. Rio de Janeiro: Editora Fiocruz, 197-208).

Laranjeira, R., Madruga, C. S., Pinsky, I., Caetano, R., \& Mitsuhiro, S. S. (2014). II Levantamento Nacional de Álcool e Drogas (LENAD) - 2012. São Paulo: Instituto Nacional de Ciência e Tecnologia para Políticas Públicas de Álcool e Outras Drogas (INPAD), UNIFESP.

Löwy, I. (2013). Le genre du cancer. Clio: femmes, genre, histoire. 37, 65-83.

Mäkelä, K. (1991). Social and cultural preconditions of Alcoholics Anonymous (AA) and factors associaded with the strength of AA. British Journal of Addiction, 86(1), 1405-1413.

Nakamura, E. (2009). O lugar do método etnográfico em pesquisa sobre saúde, doença e cuidado. Antropologia para Enfermagem. São Paulo: Manole, 15-34.

Neves, D. P. (2004). Alcoolismo: acusação ou diagnóstico? Cadernos de Saúde Pública, Rio de Janeiro, 20(1): 714.

Sarti, C. A. (2005). A família como espelho: um estudo sobre a moral dos pobres. 3. ed., São Paulo: Cortez Editora.

Soares, B. M. (1999). Mulheres invisíveis: violência conjugal e novas políticas de segurança. Rio de Janeiro: Civilização Brasileira. 
Victora, C., Knauth, D., \& Hansen, M. (2000). Pesquisa qualitativa em Saúde: uma introdução ao tema. Porto Alegre: Tomo Editorial.

World Health Organization (WHO). (1994). Qualitative research for health programmes. Geneva: division of mental health 